\title{
NON-NAÏVE ORGANIZATIONAL POSITIVITY THROUGH A GENERATIVE PARADOX PEDAGOGY ${ }^{1}$
}

\author{
Miguel Pina e Cunha \\ Universidade Nova de Lisboa \\ miguel.cunha@novasbe.pt \\ Ace Volkmann Simpson \\ Brunel Business School \\ Brunel University London \\ ace.simpson@brunel.ac.uk \\ Arménio Rego \\ Católica Porto Business School \\ and Instituto Universitário de Lisboa, ISCTE-IUL, Business Research Unit \\ arego@porto.ucp.pt \\ Stewart Clegg \\ University of Stavanger \\ $\&$ Nova School of Business and Economics \\ Universidade Nova de Lisboa \\ s.clegg@uts.edu.au
}

\footnotetext{
1 This work was funded by Fundação para a Ciência e a Tecnologia (UID/ECO/00124/2013, UID/ECO/00124/2019, UID/GES/00731/2019, UID/GES/00315/2019, and Social Sciences DataLab, LISBOA-01-0145-FEDER-022209), POR Lisboa (LISBOA-01-0145-FEDER-007722, LISBOA-01-0145-FEDER-022209) and POR Norte (LISBOA-01-0145FEDER-022209).
} 


\begin{abstract}
Positive Organizational Scholarship (POS), with positivity as a core conceptual component, is a major innovation in recent decades in management and organizational studies. Just as organization is an inherently paradox laden process, so too, we argue, is positivity. Yet in classrooms and in practice, POS is mostly taught in a manner that accepts only one side of the paradox, that which, at first glance, appears positive. Against such linear approaches we propose another possibility: teaching positivity through a pedagogy of generative paradoxes emergent from creatively harmonising the energy of competing and interdependent positive and negative tensions. In the process we extend the notion of generative paradox as discussed in paradox literature by embracing the notion of generativity as discussed in POS theorizing where it is associated with organizational processes that facilitate outcomes of collective flourishing, abundance, wellbeing, and virtue. Our proposed three-part generative paradox pedagogy contributes to the literatures on POS, organizational paradox and management learning.
\end{abstract}

Keywords: positive organizational scholarship, paradoxes, positivity, virtue, dualities, generative paradox, pedagogy 


\section{INTRODUCTION}

Management and organization studies has displayed a growing interest in Positive Organizational Scholarship (or POS, see Cameron et al., 2003a; Cameron and Spreitzer, 2012; Roberts, 2016; Spreitzer et al., 2019). Despite the rapid growth in interest, the field's shortcomings, including those evident in learning and teaching, leave open the possibility of naïve expectations in terms of its application (Collinson, 2012). A positive project can easily lead to a form of binary dualism that is negative about negativity, overlooking the generative potential of the negative in certain contexts (Fineman 2006) [e.g., employees organizing against injustice can be understood as a positive practice, as is a focus on organizations addressing workplace suffering (Kanov, 2021)]. Another related critique is to overlook the potential negativity in positivity (e.g., when the use of positive practices mask structurally embedded dissatisfaction and inequity). Positivity is not one-dimensional: positive and negative co-exist as paradoxical forces in tension. Paradox, defined as persistent oppositions between mutually defining forces (Smith and Lewis, 2011), has been recognized as relevant to POS (Cameron, 2008, 2017). POS scholars such as Cameron and Caza (2004: 732) have presented POS as "concerned with understanding the integration of positive and negative conditions, not merely with an absence of the negative". As they elaborate, POS "advocates the investigation of both types of phenomena in relation to one another, but with a special emphasis on uncovering and interpreting what is affirmative in organizations" (Cameron and Caza, 2004: 732). Caza and Carroll (2012: 975) are more nuanced view in their recognition that a priori characterisation of something as positive or negative is problematic. Instead, they offer some questions to prompt reflexivity and dialogue on the positivity/negativity of a given situation or phenomenon, including these: "In defining positivity, which groups might have differing views? How many of those groups are included in the conversation? How could the excluded parties be involved?" Such nuance, however, is often absent in POS theorising, teaching and learning. Instead, binary dualism often prevails. 
Pedagogically, rather than teaching positivity as a universal application of one-best-way approaches, might instead stress the advantages of a 'paradoxical mindset' (Miron-Spektor et al., 2018). What is revealed as positive is not always inherent to the situation, but rather in how managers deal with the paradoxical tensions and ambiguities encountered in the everyday organizational life. Students tutored in paradoxical thinking, "the ability to comprehend the complicated interplay of opposites" (Dehler et al., 2001: 506), learn the limits of certainty and unipolar solutions. Paradoxical thinking recognises that what appear to be solutions may well be temporary; that paradoxes are constitutive of significant elements of organizational life and that coping with frustration, ambiguity and doubt, in the face of paradox, may be wise.

In the spirit of POS, we argue for teaching generative paradoxes, which are distinct from other paradox types. In the educational context, Robertson (2005: 182) distinguishes between paradox types by explaining that "conflict, compartmentalized paradoxes, and generative paradoxes are seen to represent points on a continuum". The key distinction between compartmentalized and generative paradoxes is that with compartmentalized paradoxes, the poles of the paradox "co-exist by taking turns. They do not feed each other, but at least they do not fight each other" (p. 187). In contrast, "[w]ith generative paradoxes, the two sides of the contradiction feed each other. They are related in a mutually beneficial way" (p. 187). In sociology, Blyth (2013: 211) draws distinction between "a generative rather than a general paradox". While in organizational studies Berti and Simpson (2021: 252) draw attention to pragmatic paradoxes as "the dark side of organizational paradoxes". These arise from competing demands imposed by the powerful on those with limited agency due to dependence and limited opportunity to discuss or negotiate, creating Catch-22 situations (where contradictory bureaucratic requirements force victims into vicious loops), or double binds (where contradictory orders such as "take initiative" that must be disobeyed to be obeyed). Against these distinctions, our concern in this paper is generative paradoxes. 
Organizational scholars recognise that paradoxes operate as generative paradoxes when the conflict between tensions is harmonised to create an emergent power that stimulates innovative mutually advantageous outcomes (Andriopoulos and Lewis, 2009; Hargrave and Van de Ven, 2017, Berti et al. 2021). We expand on this paradox understanding of generativity by embracing the notion of generativity as frequently discussed within POS. Quinn, Spreitzer and Lam (2012: 48) describe generativity as intrinsic to POS objectives: "POS is focused on the generative dynamics in organizations that lead to the development of human strength, foster resiliency in employees, and cultivate extraordinary individual and organizational performance”. Cameron and Sprietzer (2011: 4) similarly explain that "POS has a bias toward life-giving, generative, and ennobling human conditions". Glynn and Watkiss (2011: 617) describe generativity within this expanded POS orientation as "generative potency (i.e., the capability to enrich collective strengths, virtues, and capabilities in organizations)".

We argue that by integrating the POS objective of studying generative organizational dynamics with the notion of generative paradoxes, management students can be better served in their learning about POS. By generative paradox pedagogy we refer to a learning orientation that appreciates paradox as constitutive and integral of organization, one mindful of the complexities inherent to addressing paradoxes but in a manner the promotes mutually beneficial flourishing, thriving and wellbeing, while simultaneously being mindful of "the processual, holistic and historical qualities of generativity" (Carlsen and Dutton, 2011: 20). Virtue is relevant to this process with Cameron, Dutton and Quinn (2003: 30) arguing that the notion of organizational virtue as one of the generative ideas of POS: "a second generative idea is that some virtues are, by nature, attributes of organizations, not [just] individuals", a point noted by paradox scholars such as Smith, Lewis, Jarzabkowski and Langley (2017). Given the necessary and complementary presence of opposing poles (Bednarek et al., 2016), leveraging paradoxes in a manner that promotes generativity can challenge organizational agents to draw upon the strength of virtues (March and Weil, 2003) such as wisdom, courage, humanity, justice, 
moderation and transcendence (Rego, Cunha and Clegg, 2012). Accordingly, we theorise virtue as intrinsic to this generative paradox pedagogy in two ways: as resource and as an indicator. As a resource, agents draw upon virtues such as wisdom, strength and courage as an indication of generative intent as they seek to integrate and leverage paradoxical tensions as generative paradoxes. As an indicator, virtue signals the successful mutual reinforcing of the negative and the positive as generative paradoxes (from which virtues such as transcendence, humanity, or justice might be emergent).

Overall, we hold that a generative paradox orientation offers a more nuanced and realistic understanding of positive organizations as being composed of dynamic combinations of positivity and negativity. Further, a generative paradox pedagogy affords an opportunity for management educators to draw from both critical and positive traditions without diminishing either. Students can explore nonnaïve generative paradox as an essential element of the craft with which they will manage. Specifically, generative paradox defines positivity not in terms of the presence or absence of some attribute rather focuses on how tensions between interdependent, yet oppositional forces can be leveraged to contribute towards generative outcomes. To explore our theme, we organize the paper around four main sections. We start by delineating the role of paradox in a theory of organizational positivity, prior to introducing the notion of a generative paradox pedagogy that involves three conceptual moves. In a first conceptual move, we challenge students through different types of paradoxical organizational problems that highlight tensions between the needs of the organization and other stakeholders, such as employees, customers and the broader community. In a second move, we present students with a choice between analytically dualist and generative approaches to paradox, to demonstrate how a generative paradox approach makes tensions salient so that their complexity can be grappled with more creatively to identify opportunities for promoting wellbeing. Building on this, given the importance of virtue as a primary theme in POS, a third conceptual move is dedicated to developing student's virtue literacy and capability. We analyse how virtues emerge from viewing challenges and formulating solutions 
through a generative paradox lens. In the final section, we set out a research agenda for teaching positivity using our proposed generative paradox pedagogy.

\section{POSITIVITY AND GENERATIVE PARADOX}

Organizations and their management have been recognized as inherently paradoxical (Lavine, 2014; Putnam et al., 2016). For instance, organizations often experience both continuity and change, adopt both a global and a local focus, and pursue both competition and cooperation goals (Ashforth et al., 2014). Managers who address just one pole of an opposition lose the potential generative power and creativity of being in tension. Paradox offers a metatheoretical lens that can facilitate addressing the tensions pervading organizational life. Considering such paradoxicality, an open and unresolved issue in the POS agenda concerns the pedagogy of positivity in relationship to negativity. Paradoxical views of the positive may stimulate the ability to think independently and creatively, to tolerate alternative worldviews, avoiding unidimensional perspectives entertained by overly instrumental training (Harrison et al., 2007; Petriglieri and Peshkam, 2021). A paradox approach is also emancipatory in the sense that it demonstrates that nobody, including experts or instructors, has the solution to a paradoxical problem. Students are accordingly invited to see themselves as independent learners (Dehler et al., 2001) using curiosity and creativity (Carlsen et al., 2012; Grant, 2021) to make sense of problems. Prefabricated recipes rarely solve paradoxical challenges, even (or mainly) when they are portraited as being positive and virtuous. Students can be invited to think critically, from multiple vantage points (Grey and Mitev, 1995). Awareness of the irreducibility of complexity can accentuate several effects. First, that the positive and negative are entangled; second, that there is an inevitable distance between theory and practice, not as a flaw in the educational system but as an existential condition. Organizational life is a lived experience (Simpson et al., 2021).

There are several approaches to theories of organization that avoid a linearity bias in constituting the relationship between positivity and negativity as one that assumes that the more positive the better (De 
Langhe et al., 2017; Lam et al., 2014; Stouten et al., 2013). An analysis of virtue in organizational life nicely illustrates these relations. A manager for whom courage entails reckless risk-taking or for whom caution leads to over- indecision (Worline, 2012) displays a negative positivity. That too much of a good thing is bad, even dangerous, is captured in notions such as overconfidence (Ehrlinger et al., 2016), false hope (Polivy and Herman, 2000), unrealistic optimism (Shepperd et al., 2015; Weinstein, 1980) as well as the realization that the relationship between moral humility and moral outcomes may be curvilinear (i.e., inverted U-shaped; Smith and Kouchaki, 2018). For example, "humility" can be practiced in inappropriate ways when it projects the image of the manager as weak, lacking self-worth and as grovelling, much as the oleaginous chaplain, Obadiah Slope, in Trollope's (2016) Barchester Towers. Positivity and negativity are nuanced categories, confronting managers with challenging paradoxes (Joosten et al., 2014). In this sense, a generative paradox perspective highlights that a brave leader is likely both fearless and not fearless (Heil, 1996). A leader's courage paradoxically involves not only deliberation about doing the right thing and carrying it out well but may also involve a "skill", a "special kind of calculated risk taking", which is learned and defined "over a period of time, often decades" (Reardon, 2007, p. 60), a skill that is aware of personal risk and the presence of fear (Harbour and Kisfalvi, 2014). In Long Walk to Freedom, Nelson Mandela (1995, p. 622) writes: "I learned that courage was not the absence of fear, but the triumph over it. I felt fear myself more times than I can remember, but I hid it behind a mask of boldness. The brave man is not he who does not feel afraid, but he who conquers that fear". Brooks (2015, p. A31) notes that a trait that marks leaders with passion is that "they have high levels of both vulnerability and courage. (...) [They] have the courage to be themselves with abandon. We all care what others think about us. People with passion are just less willing to be ruled by the tyranny of public opinion."

A focus on positivity in management learning that stigmatizes its absence is both a negative and an unrealistic approach, leading to a form of romantic scientism (Brown et al., 2014). It is unrealistic because it is conceptually inconceivable that organizations and individuals have no negativity, a 
statement that signals the fact that learners should not misconceive what a focus on the positive might entail. It is negative because teaching inconceivable notions, such as false optimism and overconfidence, is dysfunctional and dangerous. Doing so is likely to produce charlatans imbued with faith in their possession of prowess that will rarely withstand critical scrutiny. The imposition of mutually impossible managerial demands for positivity creates pragmatic paradoxes (Berti and Simpson, 2021) inscribed in choices "between non-existent alternatives" (Putnam et al., 2016: 83), causing paralysis. Such paralysis is the opposite of generativity (Marcia, 2002).

The psycho-social notion of generativity, defined as "the fact or quality of contributing positively to society through activities such as nurturing, teaching and creating" (Oxford English Dictionary, online), is a key element of POS theorising that is also central to paradox theory, though traditionally with a narrower focus on creativity and innovation (Berti et al. 2021). Workman (2011: 789) describes the generative focus of POS: "Positive organizational scholarship seeks to understand how organizational structures and processes establish the foundation and conditions for the emergence of generative and capability-enhancing processes". Cameron (2017:218) describes three generative areas of convergence in the notion of the positive "as the term has been employed in POS and applied to POS". One concerns "extraordinarily positive outcomes" (p. 218) exceeding normal performance expectations. Another has been "an emphasis on an affirmative bias, or towards prioritizing strengths, capabilities and possibilities rather than problems, threats and weakness" (p. 218). The third "relates to the concepts of virtuousness and eudemonism" (p. 218). We see potential for all three objectives in a broader conceptualisation of generative paradoxes, underpinning a POS inspired generative paradox pedagogy that seeks to leverage organizational tensions in a manner that produces outcomes of collective thriving, wellbeing and virtuousness.

An embrace of generative paradox, even if unconscious, is seen in the responses of companies to industry challenges, such as Patagonia's response to the environmental and financial challenges facing 
the garment industry (O'Rourke and Strand, 2017). Rather than choosing one value (profit) over the other (sustainability and social responsibility), as was standard industry practice, Patagonia invested in research and development to identify new environmentally friendly technologies. More surprisingly, Patagonia shared these technologies with competitors to facilitate industry transformation towards more sustainable practices (Casadesus-Masanell, Kim and Reinhardt, 2010). The company is also committed to Fair Trade practices, paying above market prices and fund contributions for the workers making their certified Fair-Trade range of products (Walske and Tyson, 2015). The generative paradox of this case is not only that by pursuing not just profit but profit through initially more expensive virtuous practices Patagonia also become highly profitable in the longer term, but also that Patagonia leveraged tensions of competition and cooperation by sharing practices to improve the industry rather than seeking to be proprietary.

As generative paradoxes are a paradox sub-category, our proposal for a generative paradox pedagogy can build on important existing efforts to articulate a paradox pedagogy (Knight and Paraoutis, 2016; Lewis and Dehler, 2000; Smith et al., 2012; Simpson et al., 2021). Nonetheless, paradox pedagogy remains an under-developed area. Further, while two of the founders of POS, Quinn and Cameron, were also some of the earliest theorists of organizational paradox (for examples see Cameron 2008, 2017; Cameron et al., 2014; Quinn 1988; Quinn and McGrath, 1985), a paradox pedagogy for POS nonetheless remains unexplored. We address this limitation with our proposal for, not just another paradox pedagogy, but a generative paradox pedagogy highlighting that generativity is not onedimensional, rather positive and negative exist as paradoxical forces in tension. Teaching POS as if negativity in organizations were not pervasive is unrealistic. Furthermore, students unprepared to deal with negativity will likely experience a disconnect between what is taught theoretically versus what is experienced in practice, rendering formal instruction to be experienced or deemed as useless. Our generative paradox pedagogy accordingly seeks to cultivate in students a comfort with ambiguity and 
tension through a paradoxical mindset (Miron-Spektor et al. 2018) that facilitates their development of generative paradoxical solutions.

\section{ARTICULATING A PEDAGOGY OF GENERATIVE PARADOX}

Pedagogy involves not only communicating information but is also a praxis of oscillation between theory, practice, reflection, action, questioning and transformation. Paradox pedagogy promotes critical reflection and learning by testing the reasoning of a paradox's logic and the reliability of its assumptions to tackle ambiguous problems to which simple prescriptions do not apply which, in a world facing grand challenges, constitutes an important competence that should be taught, as the OECD (2018) recently argued. Paradox pedagogy may be the subject of inquiry or content; a method of transmission or new learning or insight experienced by the learner (Burnstein 1971; Hamilton 1999). Our concern is with all three, through a specific focus on generative paradoxes that entail interdependent and persistent contradictions leveraged to support wellbeing and the greater good.

A summary of the objectives and processes that distinguish a paradox pedagogy from traditional management learning approaches is provided by Lewis and Dehler (2000: 713): "In sum, learning through paradox requires analyzing contradictions, experiencing tensions, and experimenting with their management." Rather than providing students "with well-defined problems with clear solutions, the instructor serves as facilitator, fostering creative tension and opportunities for students to critique and rethink oversimplified concepts, assumptions, and issues and develop more complicated and insightful understandings" (p. 713). Smith et al. (2012) articulate a paradox pedagogy framework which focuses on classroom challenges and fieldwork experiences that facilitate the development of three essential skills: paradox acceptance, differentiation and integration. Acceptance entails that when a mentality of abundance is recognised, simultaneous competing demands can be possible; differentiation entails developing an awareness of the distinct value of each competing demand, while integration entails developing openness, trust and sensitivity to facilitate bringing competing demands 
together in a productive manner. Simpson et al. (2021) build on the above by proposing engaging with art as a process for learning about paradox through applied experiential learning. Knight and Paraoutis (2016) suggest that paradox pedagogy is ideal for management students' learning as a type of higher order meta-theory compatible with four threshold learning attributes that promote higher level learning. These are (1), paradox is transformative in changing perceptions; (2) it is irreversible, in that once learned, the paradox perspective cannot be unlearned; (3) it is integrative in that it can be applied across topics and disciplines and (4), it is bounded in that not every contradiction is a paradox.

We seek to integrate the above paradox pedagogy theorising with the objectives of POS with a proposed generative paradox pedagogy by teaching management students to be aware of inherent interdependent tensions and find ways to creatively integrate them in a manner that promotes generative organizational outcomes in line with the objectives of POS. In the following sections we advance our proposed generative paradox pedagogy in three conceptual moves (see Figure 1 for a visual representation). First, to make the challenges and contradictions of management and POS real, we propose exposing students to real world business challenges where difficult choices need to be made, typically between the wellbeing of a company versus the wellbeing of employees, society or the environment. Second, we suggest presenting students addressing the challenges with the choice of analytic dualism or generative paradox, allowing them to note how an approach deploying generative paradox grapples with tensions, producing more creative solutions that benefit a broader group of stakeholders. Third, we suggest introducing students to the concept of virtue, given its centrality in POS (Cameron and Winn, 2012). We stress the virtue framework introduced by Peterson and Seligman (2004). Using this framework, students can engage in identifying the virtue(s) that are drawn upon and emerge from a generative paradox approach to addressing business challenges. With these three moves we present our notion of generative paradoxes as both nuanced and helpful for learning and teaching POS. 
$<<$ Figure 1 about here $>>>$

\section{CONCEPTUAL MOVE 1: CHALLENGES OF POSITIVE ORGANIZATIONS}

A generative paradox pedagogy can be best applied to POS learning and teaching by putting students in groups in which they discuss, debate or role play real world business cases posing paradoxical challenges. Scenarios may be wide ranging in representing varied industries and specific contingencies (such as the COVID-19 pandemic). The types of issues highlighted typically might include tensions between the profitability or survival of an enterprise against the needs of loyal employees; they could include tensions between the interests of other stakeholders opposed to the enterprise's strategies; they might address harmful social or environmental impacts of an organization's business model (see Table 1 for two sample scenarios: global hotel and technology giant). We use the cases to initiate the type of discussion that might be steered in the classroom by asking students to think critically. In the classroom we would present the case and encourage the students to develop analysis in their groups with webbased research and propose positive solutions.

$<<<$ Table 1 about here $>>>$

Requiring student groups to propose positive solutions to the challenges in such scenarios, as well as to justify and defend their responses against the solutions arrived at by other peer groups, makes for a nuanced but also a lived, visceral learning experience. Positivity is accordingly paradoxically experienced less as an abstract idea and more as a real and uncomfortable source of negative tension (Vince and Broussine, 1996). The deeper effect is a pedagogy that focuses less on information transfer and more on providing experiences that facilitate transformational shifts in thinking (Snook, 2008). To aid students in arriving at positive managerial responses to these challenges, we suggest providing them with two options: dualistic opposition and duality as generative paradox. 


\section{CONCEPTUAL MOVE 2: COMPARING ANALYTIC-DUALISM AND GENERATIVE PARADOX}

Our second conceptual move entails highlighting to students the interplay between positive and negative as either analytic dualistic opposition or duality conceived as generative paradox.

\section{Analytic dualism}

The adoption of a dualistic approach affirms one side of a paradox pole while denying the other. Organizations and their members, viewed through a naïve application of POS (Cunha et al., 2020), are placed in simplistic binary categorizations of the either-or type: something is either positive or it is not (Smith and Lewis, 2011). From this perspective, positive and negative are separate forces. Such an orientation is expressed in individual terms when executives are accused of corporate crime or upheld as heroic role models (Wray-Bliss, 2012), or when one set of values by which people should live is defined as good and all else as bad, a problem often associated with extreme faith, whether in ideology or religiosity.

The inherent tensions underpinning categorizations premised on either displaying or not displaying fundamental values are powerful because they render positive and negative as clear-cut characteristics with well-defined boundaries. The simplicity of analytic dualism comes at the cost of ignoring the grey areas, where categories get blurred (Cunha et al., 2010), where wrongdoing is normalized (Palmer, 2012), where even the best leaders express their flaws (Rego et al., 2012). Binary-dualism is present in media accounts of organizations that easily construct heroes and villains, as well as in the notion of "bad apples" (Trevino and Youngblood, 1990) or, at a higher level of analysis, bad barrels. When we apply dualism to the scenario discussed earlier of the global hotel business going bankrupt (see scenario \#1, Table 1), it does not offer helpful solutions. Laying off employees is undesirable but so is letting the organization go bankrupt. Similarly, with the 
technology giant (scenario \#2), a dualistic response to positivity might suggest the undesirable solution of taking on fewer clients who can afford to pay (so as not to overburden staff or staddle the organization with debt), but then so many businesses would be left unable to transition to an online environment during a moment of crisis. In each case, the leadership team would be stuck in paralysis between two undesirable choices with no clear pathway. Dualism seeds powerful narratives widespread in the view that organization in general and business, in particular, are inherently exploitative. The concept of a dualistic force reliant on stories of heroes and villains is a common cultural trope, despite these categories not being fixed essences (Rhodes and Bloom, 2018). Heroes fall from grace and become villainous, while villains redeem themselves and become heroes. Explanations that rely on dualistic opposition are problematic: for instance, success stories tend to be used to build larger than life characters in managerial fictions that seize on a one-dimensional simplification of complex characterizations, situations and their paradoxes (Jackall, 1988). Not only the appeal but also the limits of binary either-or thinking may be critically explored using dualistic approaches. The dualistic approach is to a greater or lesser extent paradox denying, viewing paradoxical tensions from a perspective of conflict or compartmentalization. Dualistic views might help with understanding management practice and decision processes; however, none of them will solve the paradoxical tensions that underlay the organizational activities in the longer term, as a defining feature of paradox is persistence (Putnam et al., 2016). Either-or choices are common but, from a paradox view, selecting only one pole of a paradox while denying or compartmentalizing the other will generally have debilitating effects. Differently, in our pedagogical framework the paradoxical (duality) approach explores positivity as a process of recognizing and accepting contradictions to transcend them to leverage the opportunity of generative paradoxes for organizational benefit as well as human-social-environmental wellbeing, which we explore next.

\section{Generative paradox}


A generative paradox pedagogy recognizes both the positive and the negative elements of a paradox as mutually constituting, composing a duality. In a duality, tension is present but does not preclude the reciprocal constitution of opposing forces, unlike dualism's concern with doubleness with no overlaps (and/or). Duality refers to a state of mutual interdependence in tension, double interacts, persistent relating (and/and). In duality each element contains the seed of its opposite, such as the positive and the negative. In using a generative paradox pedagogy for studying positivity, the focus needs to be on understanding how positivity in organizations is practiced via synergy and trade-off ( $\mathrm{Li}, 2016$ ). Synergy represents a higher-level articulation of opposites that transforms tension into complementarity. Trade-off refers to the oppositional side of paradox, which produces tension, psychological discomfort (Pradies et al., 2021), unbalancing (Vince and Broussine, 1996) and action inhibiting paralysis (Smith and Berg, 1987).

Another way of thinking about paradox tensions is distinguishing between a perspective of conflict, paradox compartmentalization (embracing one pole or another at a time) or generative paradox. A person "experiences these fundamental contradictions as exhausting conflicts or as generative paradoxes depending on the degree to which" they are "able to integrate the two sides of the contradictions and have these two sides relate productively with each other" (Robertson 2005: 138). Viewed through a lens of generative paradox, positivity is an ongoing process in which established balances can be unsettled, dualities framed as dualisms, positives becoming negatives. With generative paradoxes, the positive is not approached through the denial or the absence of the negative (Putnam et al., 2016) but rather in their dynamic interplay in producing generative outcomes.

Applied to the scenarios discussed earlier, a generative response accepting paradox opens new possibilities. Take the effect of COVID-19 on the hotel industry as a case in point (scenario \#1, which was based on the case of Hilton). Virtually all global hospitality companies laid off staff as travel was brought to a virtual standstill, including Hilton which made 22 per cent or 2100 corporate workforce 
redundant globally, in addition to extending furloughs, reducing hours and decreasing corporate pay (Kane et al., 2020; Frauenheim et al., 2020). However, Hilton did something else that set it apart and helped it maintain high employee trust and engagement. Initiating partnerships with leading companies that had job openings created by the pandemic, Hilton placed thousands of employees in temporary positions across the globe, with a promise of extradited recruitment once the crisis passed. Other employee related initiatives included activating Team Member Assistance to distribute cash to employees affected by COVID-19 as well as continuing the provision of health coverage to furloughed employees. CEO Chris Nassetta cut his salary in solidarity with employees made redundant and executive committee members took a fifty per cent pay cut. To provide community support, the company partnered with American Express to donate "1 million hotel room nights to frontline medical professionals leading the fight against COVID" who might be concerned about returning home and exposing family members to the virus and arranged for these guests to have healthy fresh meals (Frauenheim et al., 2020: 14). Hilton accordingly identified paradoxical ways to care for employees by firing them but also finding them other employment while caring for the wider community by providing free rooms to frontline health professionals. Such investment in maintaining a high-trust culture broader community care saw Hilton employees rate the company as one of the World's Best Workplaces 2020 (third in global rankings).

The commitment of the global technology giant, towards its employees and customers during the COVID pandemic is another example of generative paradox (scenario \#2, this case was based on Cisco). Employee's ability to deal with increased demands was founded on the history of trust and sense of psychological safety that Cisco had consciously cultivated among employees prior to the pandemic (Frauenheim et al., 2020). In the crisis, weekly check-ins in which CEO Chuck Robbins listened to employee concerns and responded to tough questions on uncomfortable issues (including that of racism/George Floyd, that was dominating public attention) maintained this trust and sense of safety. Further concern was demonstrated through a company-wide survey of employee workplace 
experiences. Cash strapped customers were supported with finance arrangements for their purchases. Rather than focusing on short term payments, Cisco dared to trust that clients would make good on their payments later. Cisco employee ratings saw the company take first place in the World's Best Workplaces 2020 rankings.

A paradox of these two scenarios is that pursuing broader positive ends above that of profit will likely enable them to be more profitable in the longer term as the pandemic eases. Rather than choosing just one horn of the paradox and denying the other, in the scenarios creative ways of embracing both were found through generative paradox acceptance initiatives. These solutions may not have emerged from conscious use of a generative paradox lens; nonetheless, they exemplify its application. The representation of positivity in organizations resides in the ways in which the constitutive tensions that arise from phenomena that imply and negate one another are handled in practice. In the next section, in a third conceptual move, we consider the emergence of virtue from generative paradox.

\section{CONCEPTUAL MOVE 3: IDENTIFYING EMERGENT VIRTUE}

Virtue is a primary area of concern in POS (Cameron and Winn, 2012). In our generative paradox virtue is conceptualised both as a resource drawn upon by agents facing the challenge of generatively integrating paradox tensions, as well as an indicator, where the emergence of virtue signals the successful leveraging of paradox tensions as generative paradoxes. Accordingly, the third conceptual move further enhances student's competency by identifying the virtues emergent in generative paradoxical solutions to the cases discussed. Peterson and Seligman (2004) identified six ubiquitous virtues, based on extensive qualitative and quantitative factor analyses: wisdom, courage, humanity, justice, temperance, and transcendence. Transplanting this framework from its psychological roots to the organizational context (for a discussion of the practice of these virtues within the organizational/leadership context, see Rego et al., 2012), examples of one or more of these six virtues (and the respective character strengths) may be identified as emergent in generative paradox informed 
solutions to business challenges. Next, for the sake of brevity, we narrow our analysis to just two virtues, those of humanity and courage.

\section{Humanity}

Humanity, "interpersonal strengths that involve the consideration of others" (Wright and Goodstein, 2007: 951), is premised on caring for and befriending others, through expressions of compassion and generosity. The example of Hilton (scenario \#1) demonstrates that kindness and generosity do not entail irrational sentimentality or inappropriate boundaries and constraints (Nussbaum, 2003). Being humane requires a paradoxical combination of compassion with wisdom and strength (Simpson and Berti, 2020), which may be expressed in ways that are selfless or strategic, interpersonal or institutional (Araújo et al., 2019). Research on paradoxical leadership identifies cases of leaders whose toughness was not incompatible with a sense of care for their people (e.g., Zhang, Waldman, Han and Li, 2015). Grant (2019) wrote of Bill Campbell, who was VP of Marketing and board director for Apple Inc., and CEO of other companies: "he dished out exactly the kind of tough love you'd expect from a football coach: he tore her proposal apart, pushed her to come up with something stronger, and then stood up for her”. The former Xerox CEO Anne Mulcahy was described as both tough and empathic (Von Bergen, 2013), a paradoxical combination that helped her to recover the company. Managing the tensions between empathy and blind justice (Waytz, 2016), respect and discipline (Rogers and Ashford, 2017), means and ends (Keating, in O'Brien, 2005), is required. As Gu et al. (2020) suggested, authoritarian leadership combined with benevolence or morality (i.e., "tough love") influences employee creativity.

\section{Courage}

Courage, "emotional strengths that involve the exercise of will to accomplish objectives in the face of adversity" (Wright and Goodstein, 2007: 951) is a "difficult virtue" (Worline, 2012) involving the combination of bravery and mindful deliberation (Rate et al., 2006) because bravery without mindful deliberation is not true courage but rash recklessness. The generative 
paradoxical solution of Cisco in accepting the risk of giving employees a platform to publicly raise concerns to the CEO in regular open forums demonstrated courage (scenario \#2). The courage was in trusting employee-employer relationships while the long-term finance arrangements given to clients during a financial crisis demonstrated trust in the business-client relationship. As March and Weil (2003) theorize, courage can be dangerously close to insanity, as in the orientation to crash through or crash. Courageous leaders may be extremely brave but their bravery, per se, is not necessarily good. As Mahoney (1998: 190) argued, "Paradoxical as it may sound, there may be a closer connection than at first appears between courage and caution, or equally paradoxically, proper moral courage may lie in taking due thought and care in all one's actions". The Cisco scenario demonstrates courage by taking on the challenge (and added cost). Simultaneously, courage also cautions in that the company pursued long term strategies - investing in people in the present for greater, more sustainable profitability into the future. Bravery in the absence of caution can be problematic.

\section{DISCUSSION}

The paradoxical relationship between positive and negative has been explicitly presented as defining POS (Cameron, 2008, 2017). However, despite the presence of paradoxical tensions in positive themes and constructs, paradox and its conceptual and practical implications for a POS pedagogy have been under-theorized. Given that management research on topics situated inside the conceptual boundary of POS are rich in references to tension and paradox, this gap is problematic. The adoption of a generative paradox pedagogy offers new and relevant pathways for the teaching and learning about positivity in management education, as well as for enriching the POS discipline.

A generative paradox pedagogy focuses on acknowledging and creatively embracing tensions rather than on normative or empirical analysis (Bansal and Song, 2017). Acknowledging and embracing tensions may be seen as an expression of wisdom (McKenna et al., 2009). To see paradox as generative requires embracing paradoxical interpenetrations of positive and negative in conceptualizing complex 
organizations to arrive creatively at solutions promoting wellbeing. For managers, a process of reflexivity intended to generate positive action rather than defensive reaction is necessary. The process may often feel like a personal "struggle - riddled with false starts, best intentions and self-deception, and entwined in the politics of pragmatism, idealism, ambition and survival" (Tomkins and Nichols, 2017: 253). Such a pedagogy characterizes several distinct positive approaches, including corporate sustainability (Hahn et al., 2018), responsible leadership (Miska and Mendenhall, 2018), authentic leadership (Ibarra, 2015), and servant leadership (Sousa and van Dierendonck, 2017). We will build on these contributions subsequently to develop a research agenda for a generative paradox pedagogy that explicitly ties it to positive organizational practices.

\section{Contributions of a generative paradox pedagogy}

The criticism that the positive is naïve (Fineman, 2006) can be mitigated through the adoption of a generative paradox pedagogy. A paradox perspective sees positive and negative as intertwined; one cannot exist in the absence of the other, persisting interdependence is assumed in the concept of paradox. Negative circumstances can promote positive approaches (Cameron and Lavine, 2006; Clair and Dufresne, 2007); the positive may stimulate conditions favourable to negative consequences. The co-presence of the positive and negative potentially discourages the adoption of simplified dualistic versions of POS, rightly criticised.

Generative paradoxes are distinct from other types of paradox in that they are not only characterised competing interdependent tensions, but in how they contribute towards the greater good (Blyth, 2013; Robertson, 2005; Tisdel, 2008). Rather than assuming that paradoxes are temporary and solvable (Smith, 2014) generative paradox pedagogy stresses persistence to achieve broader outcomes of enhanced wellbeing. POS' positivity can be better grasped as a process rather than as a fixed condition or state. Paradoxes inherent to generative positivity reveal how positive processes fluctuate over time, how time contributes to the unfolding of virtuous or vicious circles (Masuch, 1985; Tsoukas and 
Cunha, 2017). The persistence of paradoxes is important for management students in understanding oscillations in positivity that result from persistent trade-offs and synergies. If management students and scholars develop a critical approach to learning and teaching POS (Beadle et al., 2015) through a generative paradox pedagogy, its application in practice will necessarily involve both in developing self-leadership. To be positive is not a demonstration of naiveté or niceness. To the contrary, from a generative paradox perspective it involves difficult choices and a sustained effort to integrate opposing forces dynamically to achieve a greater good.

Scaling up from the individual to the collective level of analysis, the relationship between how learning and teaching using a generative paradox pedagogy informs virtuous organizational behaviour can be explored. Some members will be more competent than others in terms of creatively integrating competing demands to achieve a greater good. Research has explored how a capacity for integrative thinking (and, thus, wisdom) can be cultivated via management education (Smith et al., 2012). Such cultivation matters because it equips organizations with the capacity to articulate opposing values and outcomes fruitfully (Besharov, 2014). For the future, a significant contribution will be exploring the temporal dimensions of generative paradox. How, with time, does something positive become negative and vice-versa? How might a process be perceived as negative only to be subsequently re-appreciated as positive and constructive? Although, there is some theorising in this area (Lavine, 2012), generally, the role of temporality in the construction of positive behaviour is still under-researched. Attention to process will be important to considering how paradox response types (e.g., oscillation, separation, synthesis) interact. Future research might also explore the relationship between generative paradoxical enactment and virtuous enactment. False mastery may be invoked to manage impressions (Gaim et al., 2021) and produce toxicity rather than the virtue being projected.

\section{CONCLUSION}


POS taught as a positive projection upon the surface of a deeper structure involving interdependent positive-negative tensions can only ever be a veneer. Our proposed generative paradox pedagogy makes the inherent positive and negative tensions in organizational challenges salient, highlighting potential synergies coexisting with possible trade-offs. The aim is identifying opportunities that create broader benefits of organizational and individual wellbeing.

Our three-step generative paradox pedagogy indicates practices for (1) challenging students with complex real world business cases highlighting competing needs; (2) presenting dualist and generative paradox approaches as analytic tools for addressing these challenges, allowing students to note the nuance of the generative paradox approach and (3), analysing the virtues emerging from a generative paradox approach to these challenges. In creatively leveraging tensions to achieve greater wellbeing, a generative paradox pedagogy integrates the nuance and sensitivity to the conditions and trade-offs between conservative system maintenance by those whom March and Weil (2003) term the plumbers, wish to combine with the critical, uplifting, higher visions of poets.

\section{REFERENCES}

Andriopoulos C and Lewis MW (2009). Exploitation-exploration tensions and organizational ambidexterity: Managing paradoxes of innovation. Organization Science 20(4): 696-717.

Ashforth BE, Rogers KM, Pratt MG, and Pradies C (2014). Ambivalence in organizations: A multilevel approach. Organization Science, 25(5): 1453-1478.

Bansal P and Song H (2017). Similar but not the same: Differentiating corporate sustainability from corporate responsibility. Academy of Management Annals, 11(1): 105-149.

Beadle R, Sison AJG, and Fontrodona J (2015). Introduction-virtue and virtuousness: when will the twain ever meet? Business Ethics: A European Review, 24: S67-S77. 
Bednarek R, Paroutis S and Sillince J (2016). Transcendence through rhetorical practices: Responding to paradox in the science sector. Organization Studies, 38(1): 77-101.

Berti M, Simpson AV, Cunha MP and Clegg SR (2021). Elgar introduction to organizational paradox theory. Edward Elgar: Cheltenham.

Berti M and Simpson AV (2021). The dark side of organizational paradoxes: The dynamics of disempowerment. Academy of Management Review, 46(2): 252-274.

Besharov M (2014). The relational ecology of identification: How organizational identification emerges when individuals hold divergent values. Academy of Management Journal, 57(5): 14851512.

Blyth M (2013). Paradigms and paradox: The politics of economic ideas in two moments of crisis. Governance, 26(2): 197-215.

Brooks, D. (2015). Lady Gaga and the life of passion. The New York Times, October 23.

Brookfield S (1987) Developing critical thinkers: Challenging adults to explore alternative ways of thinking and acting. Jossey-Bass: San Francisco.

Brown NJ, Sokal AD and Friedman HL (2014). Positive psychology and romantic scientism. American Psychologist, 69: 629-632.

Cameron KS (2006). Good or not bad: Standards and ethics in managing change. Academy of Management Learning \& Education, 5(3): 317-323.

Cameron KS (2017). Paradox in positive organizational scholarship. In W. K. Smith, M. Lewis, P. Jarzabkowski, A. Langley (eds.), The Oxford Handbook of Organizational Paradoxes (pp. 216238). Oxford University Press, Oxford.

Cameron K and Lavine M (2006). Making the impossible possible. Berrett-Koehler, San Francisco, CA.

Cameron KS (2008). Paradox in positive organizational change. The Journal of Applied Behavioral Science, 44(1): 7-24. 
Cameron KS and Spreitzer GM (eds), (2012). The Oxford handbook of positive organizational scholarship. Oxford University Press: Oxford.

Cameron KS, Quinn RE, DeGraff J and Thakor AV (2014). Competing values leadership. Cheltenham: Edward Elgar.

Cameron KS (2008). Paradox in positive organizational change. The Journal of Applied Behavioral Science, 44(1): 7-24.

Cameron KS and Winn B (2012). Virtuousness in Organizations. In KS Cameron and GM Spreitzer (Eds.), The Oxford handbook of positive organizational scholarship (pp. 231-243). Oxford: Oxford University Press.

Cameron KS (2017). Paradox in positive organizational scholarship. In W. K. Smith, M. W. Lewis, P. Jarzabkowski, et al. (eds), The Oxford handbook of organizational paradox (pp. 216-238). Oxford, UK: Oxford University Press.

Cameron KS and Caza A (2004). Introduction: Contributions to the discipline of positive organizational scholarship. American Behavioral Scientist, 47(6): 731-739.

Cameron KS, Dutton JM, and Quinn RE (2003) (eds.) Positive organizational scholarship: Foundations of a new discipline. Berrett-Koehler, San Francisco, CA.

Carlsen A, Clegg S, and Gjersvik R (2012). Idea work. Oslo: Cappelen Damm.

Carlsen, A and Dutton JE (eds) (2011). Research alive: The call for generativity. In A Carlsen and JE Dutton (Eds.), Research alive: Exploring generative moments in doing qualitative research. Copenhagen: Copenhagen Business School Press.

Casadesus-Masanell, R., Kim, H. and Reinhardt, F.L. (2010). Patagonia. Harvard Business School case study, 9-711-020.

Caza, A and Carroll, B. (2012). Critical theory and positive organizational scholarship. In KS Cameron and GM Spreitzer (Eds.), The Oxford handbook of positive organizational scholarship (pp. 965978). Oxford: Oxford University Press. 
Clair JA and Dufresne RL (2007). Changing poison into medicine: How companies can experience positive transformation from a crisis. Organizational Dynamics, 36(1): 63-77.

Collinson D (2012). Prozac leadership and the limits of positive thinking. Leadership, 8(2): 87-107.

Cunha MP, Rego A, Simpson AV, and Clegg S (2020). Positive organizational behaviour: Management as a force for good. London: Routledge.

Cunha MP Guimarães-Costa N, Rego A and Clegg SR (2010). Leading and following (un)ethically in limen. Journal of Business Ethics, 97: 89-206.

De Langhe B, Puntoni S and Larrick R (2017). Linear thinking in a nonlinear world. Harvard Business Review, May-June, 130-139.

Dehler, G. E., Welsh, M. A., and Lewis, M. W. (2001). Critical pedagogy in the new paradigm. Management Learning, 32(4): 493-511.

Ehrlinger J Mitchum AL and Dweck CS (2016). Understanding overconfidence: Theories of intelligence, preferential attention, and distorted self-assessment. Journal of Experimental Social Psychology, 63: 94-100.

Fineman S (2006). On being positive: Concerns and counterpoints. Academy of Management Review, 31(2): 270-291.

Frauenheim E, Kazi C, Cesena N, Mosquera C, and Erb M (2020). World's best workplaces 2020: Rising to historic challenges. Great Places to Work. Retrieved from https://www.greatplacetowork.com/resources/reports/2020-worlds-best-workplaces

Friedman M (1970) The social responsibility of business is to increase its profits. The New York Times, September 13.

Gaim M, Clegg S. and Cunha MP (2021). Managing impressions rather than emissions: Volkswagen and the false mastery of paradox. Organization Studies, 42(6), 949-970.

George J (2014). Compassion and capitalism: Implications for organizational studies. Journal of Management, 40(1): 5-15. 
Glynn M and Watkiss L (2011) Symbolism in organizations: The generative potency of cultural symbols. In KS. Cameron and GM Sprietzer (eds.) The Oxford handbook of positive organizational scholarship. (pp. 617-628). Oxford University Press: Oxford.

Grant A (2021). Think again: The power of knowing what you don't know. New York: Viking.

Grant, A. (2019). Mentors are good. Coaches are better. Linkedin, May 2 (https://www.linkedin.com/pulse/mentors-good-coaches-better-adam-grant/)

Grey C, and Mitev N (1995). Management education: A polemic. Management Learning, 26(1): 7390.

Gu Q, Hempel PS, and Yu M (2020). Tough love and creativity: How authoritarian leadership tempered by benevolence or morality influences employee creativity. British Journal of Management, 31(2):305-324.

Hahn T, Figge F, Pinkse J, and Preuss L (2018). A paradox perspective on corporate sustainability: Descriptive, instrumental, and normative aspects. Journal of Business Ethics, 148(2): 235-248.

Hamilton D (1999). The pedagogic paradox (or why no didactics in England?). Pedagogy, Culture and Society, 7(1): 135-152.

Harbour, M. and Kisfalvi, V. (2014). In the eye of the beholder: An exploration of managerial courage. Journal of Business Ethics, 119(4), 493-515.

Harrison RT, Leitch CM, and Chia R (2007). Developing paradigmatic awareness in university business schools: The challenge for executive education. Academy of Management Learning \& Education, 6(3): 332-343.

Harbour, M. and Kisfalvi, V. (2014). In the eye of the beholder: An exploration of managerial courage. Journal of Business Ethics, 119(4), 493-515.

Hargrave TJ and Van de Ven AH (2017). Integrating dialectical and paradox perspectives on managing contradictions in organizations. Organization Studies 38(3-4): 319-339. 
Heil, J.F. (1996). Why is Aristotle's brave man so frightened? The paradox of courage in the Eudemian ethics. Apeiron, 29(1), 47-74.

Ibarra H (2015). The authenticity paradox. Harvard Business Review, 93(1/2): 52-59.

Jackall R (1988). Moral Maze. Oxford University, Oxford, UK.

Joosten A, Van Dijke M, Van Hiel A. and De Cremer D (2014). Being 'in control' may make you lose control: The role of self-regulation in unethical leadership behavior. Journal of Business Ethics, 121(1): 1-14.

Kanov JM (2021). Why suffering matters! Journal of Management Inquiry, 30(1): 85-90.

Kane GC, Nanda R, and Philips AN (2020). Hilton flips recruitment to respond to crisis. Wall Street Journal. Retrieved from https://deloitte.wsj.com/cio/2020/10/30/hilton-flips-recruitment-to$\underline{\text { respond-to-crisis/ }}$

Knight E and Paroutis S (2016). Expanding the paradox-pedagogy links: Paradox as a threshold concept in management education. In W. K. Smith, M. Lewis, P. Jarzabkowski, A. Langley (eds.), The Oxford Handbook of Organizational Paradoxes (pp. 529-546). Oxford University Press, Oxford.

Kwun A (2019). How a carpet maker became an unlikely hero of the environmental movement. Fast Company (January $2^{\text {nd }}$ ), online: https://www.fastcompany.com/90235407/how-a-carpet-makerbecame-an-unlikely-hero-of-the-environmental-movement

Lam CF, Spreitzer G and Fritz C (2014). Too much of a good thing: Curvilinear effect of positive affect on proactive behaviors. Journal of Organizational Behavior, 35: 530-546.

Lavine, M. (2012). Positive deviance: A metaphor and method for learning from the uncommon. In K. S. Cameron and G. Spreitzer (eds.), The Oxford Handbook of Positive Organizational Scholarship, 1014-1026. Oxford: Oxford University Press.

Lavine M (2014). Paradoxical leadership and the competing values framework. The Journal of Applied Behavioral Science, 50(2): 189-205. 
Lewis MW and Dehler GE (2000) Learning through paradox: A pedagogical strategy for exploring contradictions and complexity. Journal of Management Education 24(6): 708-725.

Li PP (2016). Global implications of the indigenous epistemological system from the East: How to apply yin-yang balancing to paradox management. Cross Cultural and Strategic Management, 23(1): 42-77.

Mahoney J (1998). Editorial adieu: Cultivating moral courage in business. Business Ethics: A European Review, 7(4): 187-192.

Mandela, N. (1995). Long walk to freedom. Boston: Little, Brown and Company.

March JG and Weil T (2003). On leadership. Blackwell, Malden, MA.

Marcia JE (2002). Identity and psychosocial development in adulthood. Identity: An International Journal of Theory and Research, 2(1): 7-28.

Masuch M (1985). Vicious circles in organizations. Administrative Science Quarterly, 30(1): 14-33.

McKenna B, Rooney D, \& Boal KB (2009). Wisdom principles as a meta-theoretical basis for evaluating leadership. The Leadership Quarterly, 20(2): 177-190.

Miron-Spektor E, Ingram A, Keller J, Smith WK, and Lewis MW (2018). Microfoundations of organizational paradox: The problem is how we think about the problem. Academy of Management Journal, 61(1): 26-45.

Miska Cand Mendenhall ME (2018). Responsible leadership: A mapping of extant research and future directions. Journal of Business Ethics, 148(1): 117-134.

O’Brien K (2015). Keating. Allen \& Unwin, Sydney.

OECD (2018). The future of education Skills: Education 2030. Paris: OECD Publishing.

O’Rourke, D., \& Strand, R. (2017). Patagonia: Driving sustainable innovation by embracing tensions. California Management Review, 60(1), 102-125.

Oxford English Dictionary "generativity, n.". Oxford University Press: https://www-oedcom.ezproxy.brunel.ac.uk/view/Entry/269537?redirectedFrom=generativity\& 
Palmer D (2012). Normal organizational wrongdoing: A critical analysis of theories of misconduct in and by organizations. Oxford: Oxford University Press.

Peterson C and Seligman MEP (2004). Character strengths and virtues: A handbook and classification. New York: Oxford University Press.

Petriglieri G and Peshkam A (2021). Stranger leaders: A theory of marginal leaders' conception of learning in organizations. Academy of Management Journal, https://doi.org/10.5465/amj.2019.0162

Polivy, J. and Herman, C. P. (2000). The false-hope syndrome: Unfulfilled expectations of selfchange. Current Directions in Psychological Science, 9(4): 128-131.

Pradies C, Aust I, Bednarek R, Brandl J, Carmine S, Cheal J, Cunha MP, Gaim M, Keegan A, Lê J, Miron-Spektor E, Nielsen RK, Pouthier V, Sharma G, Sparr JL, Vince R and Keller J (2021). The lived experience of paradox: How individuals navigate tensions during the pandemic crisis. Journal of Management Inquiry, 30(2): 154-167.

Putnam LL, Fairhurst GT and Banghart S (2016). Contradictions, dialectics, and paradoxes in organizations: A constitutive approach. Academy of Management Annals, 10(1): 65-171.

Quinn RE (1988). Beyond rational management: Mastering the paradoxes and competing demands of high performance. San Francisco: Jossey-Bass.

Quinn RW, Spreitzer GM and Lam CF (2012). Building a sustainable model of human energy in organizations: Exploring the critical role of resources. Academy of Management Annals, 6(1): 337-396.

Quinn RE and McGrath MR (1985). The transformation of organizational cultures: A competing values perspective. In P. J. Frost, L. F. Moore, M. R. Louis, C. C. Lundberg, and J. Martin (Eds.), Organizational culture (pp. 315-334). Thousand Oaks, CA: Sage.

Rate CR, Clarke JA, Lindsay DR, and Sternberg RJ (2007). Implicit theories of courage. Journal of Positive Psychology, 2: 80-98. 
Reardon, K. K. (2007). Courage as a skill. Harvard Business Review, January, 58-64.

Rego A, Cunha MP and Clegg S (2012). The virtues of leadership: Contemporary challenge for global managers. Oxford University Press, Oxford, UK.

Rhodes C and Bloom P (2018). CEOs should have been the fall guys; why are they still heroes? aeon, 19 October (https://aeon.co/ideas/ceos-should-have-been-the-fall-guys-why-are-they-stillheroes)

Roberts LM (2006). Shifting the lens on organizational life: The added value of positive scholarship. Academy of Management Review, 31(2): 292-305.

Robertson DR (2005). Generative paradox in learner-centered college teaching. Innovative Higher Education, 29(3): 181-194.

Rogers KM and Ashford BE (2017). Respect in organizations: Feeling valued as "We" and "Me". Journal of Management, 43(5): 1578-1608.

Shepperd JA, Waters EA, Weinstein ND and Klein WM (2015). A primer on unrealistic optimism. Current Directions in Psychological Science, 24(3): 232-237.

Simpson AV, Berti M, Cunha MP and Clegg S (2021). Art, culture and paradox pedagogy in management learning: The case of Portuguese fado. Management Learning, 1350507620988093.

Simpson AV and Berti M (2020). Transcending organizational compassion paradoxes by enacting wise compassion courageously. Journal of Management Inquiry, 29(4): 433-449.

Smith IH and Kouchaki M (2018). Moral humility: In life and at work. Research in Organizational Behavior, 38: 77-94.

Smith K and Berg D (1987). Paradoxes of group life. Jossey-Bass, San Francisco, CA.

Smith WK, Besharov ML, Wessels AK and Chertok M (2012). A paradoxical leadership model for social entrepreneurs: Challenges, leadership skills, and pedagogical tools for managing social and commercial demands. Academy of Management Learning and Education, 11(3): 463-478. 
Smith WK (2014). Dynamic decision making: A model of senior leaders managing strategic paradoxes. Academy of Management Journal, 57(6): 1592-1623.

Smith WK and Lewis MW (2011). Toward a theory of paradox: A dynamic equilibrium model of organizing. Academy of Management Review, 36: 381-403.

Smith WK, Lewis MW, and Tushman ML (2016). "Both/and" leadership. Harvard Business Review, 94(5): 62-70.

Smith, WK, Lewis MW, Jarzabkowski P and Langley A (2017) The paradoxes of paradox. In W Smith, MW Lewis, P Jarzabkowski and A Langley (Eds.) The Oxford handbook of organizational paradox (pp.1-25). Oxford University Press.

Snook S (2008). Leader(ship) development. Harvard Business School Note, N 408-064.

Sousa M and van Dierendonck D (2017). Servant leadership and the effect of the interaction between humility, action, and hierarchical power on follower engagement. Journal of Business Ethics, 141(1): 13-25.

Spreitzer G, Myers CG, Kopelman S, and Mayer D (2019). The conceptual and empirical value of a positive lens: An invitation to organizational scholars to develop novel research questions. Academy of Management Perspectives. https://doi.org/10.5465/amp.2015.0056

Stouten J, van Dijke M, Mayer DM, De Cremer D. and Euwema MC (2013). Can a leader be seen as too ethical? The curvilinear effects of ethical leadership. The Leadership Quarterly, 24: 680695.

Tomkins L and Nicholds A (2017). Make me authentic, but not here: Reflexive struggles with academic identity and authentic leadership. Management Learning, 48(3): 253-270.

Trevino LK and Youngblood SA (1990). Bad apples in bad barrels: A causal analysis of ethical decision-making behavior. Journal of Applied Psychology, 75(4): 378-385.

Trollope A (2016) Barchester Towers. Penguin, London. 
Tsoukas H and Cunha MP (2017). On organizational circularity: Vicious and virtuous circles in organizing. In M.W. Lewis, W.K. Smith, P. Jarzabkowski and A. Langley (Eds.), The Oxford handbook of organizational paradox: Approaches to plurality, tensions, and contradictions (pp. 393-412). New York: Oxford University Press.

Tweedie D, Wild D, Rhodes C and Martinov-Bennie N (2019). How does performance management affect workers? Beyond human resource management and its critique. International Journal of Management Reviews, 21(1):76-96.

Vince R and Broussine M (1996). Paradox, defense and attachment: Accessing and working with emotions and relations underlying organizational change. Organization Studies, 17(1): 1-21.

Von Bergen, J. M. (2013). Anne Mulcahy at the forum: Toughness, empathy. The Inquirer, October 15 (https://www.philly.com/philly/blogs/jobs/INQ_Jobbing_Anne-Mulcahy-at-the-ForumToughness-empathy.html)

Walske J and Tyson LJ (2015). Fair Trade USA: Scaling for impact. California Management Review, 58(1): 123-143.

Waytz A (2016). The limits of empathy. Harvard Business Review, January-February: 69-73.

Weinstein ND (1980). Unrealistic optimism about future life events. Journal of Personality and Social Psychology, 39(5): 806-820.

Worline MC (2012). Courage in organizations: An integrative review of the "difficult virtue". In K. S. Cameron and G. Spreitzer (eds.), The Oxford Handbook of Positive Organizational Scholarship (pp. 304-315). Oxford University Press, Oxford.

Wray-Bliss E (2012). Leadership and the deified/demonic: A cultural examination of CEO sanctification. Business Ethics: A European Review, 21(4): 434-449.

Wright $\mathrm{T}$ and Goodstein $\mathrm{J}$ (2007). Character is not "Dead" in management research: A review of individual character and organizational-level virtue. Journal of Management, 33(6): 928-958. 
Zhang, Y., Waldman, D. A., Han, Y.-L. and Li, X.-B. (2015). Paradoxical leader behaviors in people management: Antecedents and consequences. Academy of Management Journal, 58(2), 535-565. 


\section{Table 1}

\section{Scenarios for pedagogically engaging with virtue through paradox}

\#1 (Global hotel). You are part of the senior management team in a global hotel business, operating more than 6450 properties with more than 170,000 employees. COVID-19 has been the hospitality industry's unwelcome guest. Virtually overnight business has dried up, with plunging room occupancy rates and revenues, hotel and leisure companies have made about fifty per cent their workers redundant. Your company is not immune to these challenges. The question is, how will your team respond to addressing tensions between a commitment to preserving a positive hightrust employee culture emphasising values of hospitality, integrity and teamwork, against the competing value of company viability in the face of potential bankruptcy?

\#2 (Global technology giant). You are part of the senior management team in a global technology giant with a workforce of more than 75,000 employees. A positive effect of the COVID-19 pandemic prompting the closure of businesses worldwide as workers were sent to work from home, is that demand for your company's technology has tripled. On the negative side, this has put great pressure on your workforce to deliver, while COVID imposed shutdowns also mean current and potential customers face cash shortages. How will your team respond to addressing twin tensions between customer demand and limited staff capabilities, as well as between customer demand and ability to pay? 
Figure 1

Three moves of generative paradox pedagogy

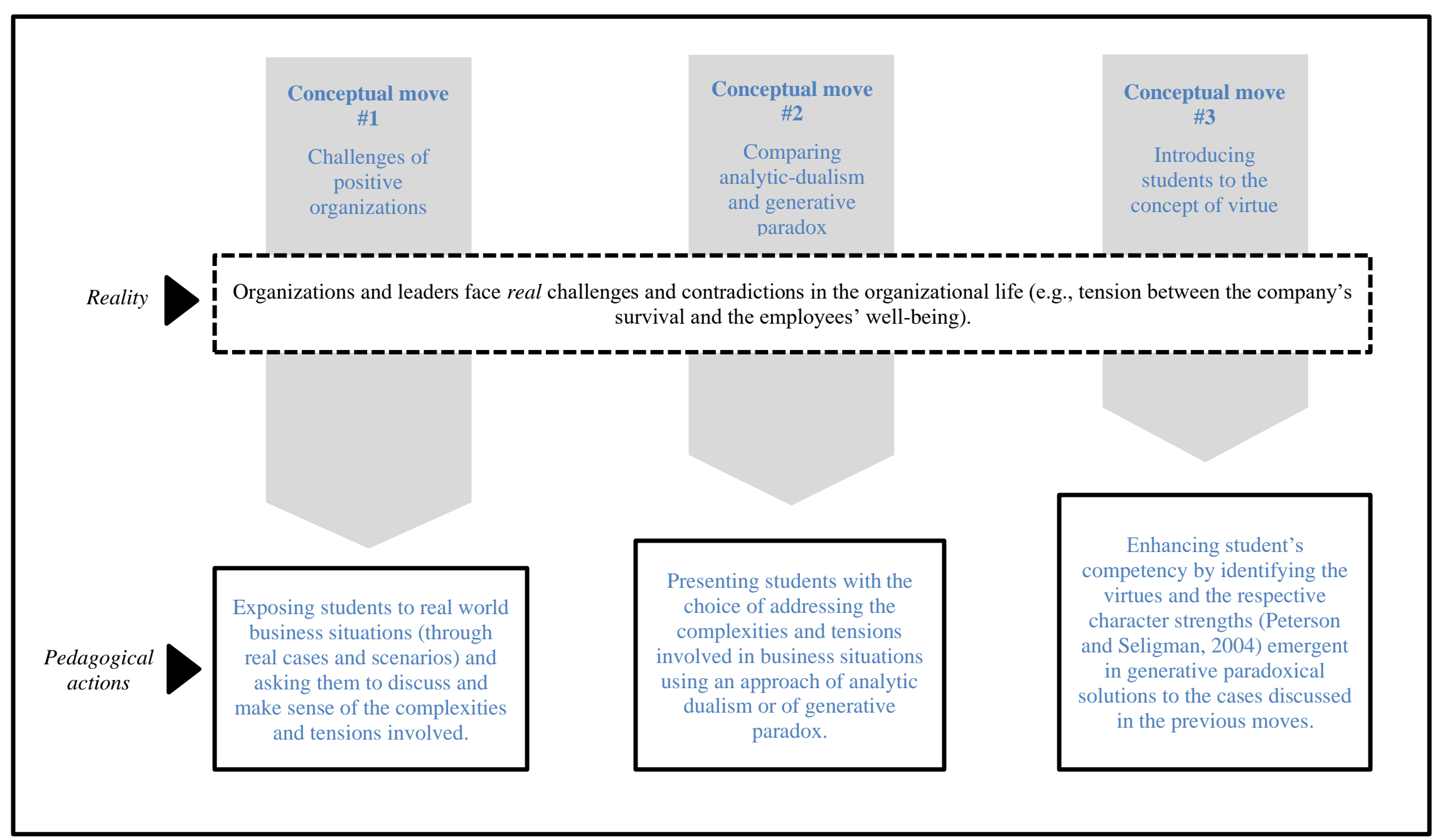

